\title{
STUDENT PERCEPTIONS OF PROJECT ESSAY GRADE (PEG) SOFTWARE
}

\author{
Michael J. Curran, Robert Morris University, curran@rmu.edu \\ Peter Draus, Robert Morris University,draus@rmu.edu \\ George Maruschock, Strayer University,george.maruschock@strayer.edu
}

\begin{abstract}
The development of increasingly sophisticated software to grade student written work (Project Essay Grade, or $P E G)$ has created a controversy within higher education. Proponents of this technology point to virtually instant grading and feedback as well as studies that demonstrate no significant differences in grades given by the computer and faculty. However opponents contend that this software fundamentally alters the nature of the faculty-student relationship and can have long term consequences for education. This study looked at how college students perceived the value of this technology and issues they had with it. The study surveyed 684 students at four colleges and revealed that perceptions generally fell into four components; faculty relationship issues, grade issues, technology acceptance, and ethical/fairness considerations. Grades were the most significant perceptual concern for students. ANOVA analysis further revealed that significant variables in overall perception of PEG software included the type of institution the student attended and their experiences in classes that utilized PEG software. Overall, students had a strong preference for faculty grading written work, although for several demographic groups there was considerable interest in PEGs.
\end{abstract}

Keywords: Project Essay Grade (PEG) software, technology acceptance, principal component analysis, student perceptions

\section{INTRODUCTION}

The use of computer software (called PEG for Project Essay Grade) to grade student work has become an increasingly challenging issue in higher education [7,24]. One side of the argument contends that allowing computers to assume a greater role in grading student written work provides many benefits to both the student and the instructor. Students benefit from increased response time for both grades and feedback. In many cases, an essay can be 'graded' and feedback provided within minutes [26]. This also allows students the opportunity to revise work in order to achieve better grades by consistently having drafts of written work graded [14,18,26]. Proponents of PEGs also contend that the grades presented by the software are statistically equivalent to those provided by actual instructors and also remove any issue of instructor bias in the grading process, thereby giving the student a more accurate assessment of his writing [10,23,25]. Supporters also point out that the use of PEGs can free faculty from hours of grading and allow them to focus more on other areas that can enhance the student experience, as well as providing additional time for other areas that faculty wish to pursue $[16,17]$.

Opponents of the use of PEG software contend that this technology may fundamentally alter the nature of the student-teacher relationship [16,23]. One of the main ways in which faculty connect with students and learn about them is through the evaluation process, especially in regard to written work [1,3]. This may be increasingly true in regard to online courses, where contact and interaction between teachers and students is often substantially less than in a campus-based class environment [6]. This may also decrease the mentoring aspect of the student-teacher relationship. Additionally, some also contend that, while a computer may give an equivalent 'grade' for written work, the substantive and personal nature of faculty feedback cannot be given by a computer.

The purpose of this study was to discover perceptions that college students have regarding the use of PEGs and evaluate the influence of these perceptions on their acceptance of this technology. As PEGs continue to develop, and there have been substantial advancements in this area in recent years, universities may consider turning to them to enhance academic programs [7,15]. They can be hugely cost effective, especially in the emerging area of MOOCs (Massive Open Online Courses) and can provide students with additional resources for success. What remains to be seen is the degree to which students are willing to accept this technology, and what perceptual areas are most significant to students in regard to PEGs. Understanding which factors are important to students can benefit designers of this software, as well as helping universities and faculty with assessing whether or not to utilize this technology. 


\section{Issues in Information Systems \\ Volume 14, Issue 1, pp.89-98, 2013}

\section{LITERATURE REVIEW}

Faculty grading of student written work has been well researched [1,28,31]. Issues in faculty grading have often included concerns over bias and fairness, turnaround time, the nature of feedback, and the amount of time and effort faculty expend on grading $[8,29,31]$. Recently, much research has been done on the emerging technology of computer software that can be used to grade student written work, providing both feedback and grades often in a fraction of the time that faculty takes. Called Project Essay Grade (PEG) software, several universities have adopted this technology, and it is expected to continue to grow $[7,18,30]$. Several studies have indicated that on issues important to students, including grades, feedback, and response time, PEGs have performed at least as well as faculty and, on the issue of response time, substantially better $[10,23,25]$. Several studies also contend that the use of PEGs can reduce instructor bias in assessment of written work and that students' impressions of the fairness and efficacy of instructors using this technology has actually increased $[5,9,22]$.

Additional studies on PEGs have focused on designing algorithms that can mimic faculty responses and deliver a grading and feedback experience to a student that simulates human responses in almost seamless fashion $[19,13,20,27]$. The technology of PEGs has continued to develop and will invariably improve, and universities have begun to look at its impact [7,23]. A number of studies indicate that it can be a benefit to students, a time saver for faculty, and a cost saving device for universities $[7,14,16,23]$. However, there seems to be little research on how students perceive the value of this technology and the degree to which they are willing to accept having a nonhuman assess and, ultimately, grade written work. The focus of this study is to look at student perceptions about this issue.

\section{METHODOLOGY}

\section{Data Collection}

A 30 question survey was developed to measure the degree to which students were willing to accept PEG software in place of faculty grading (Appendix A). The survey consisted of 23 Likert-scaled statements/questions and 7 demographic questions. The survey was distributed at four universities; these included one medium sized private not for profit, one medium sized public university, one campus based for-profit school, and one online for-profit university. After gaining institutional approval at the subject universities, several faculty members that agreed to participate in the study passed out a paper form of the survey, along with an instructional page outlining its purpose and explaining informed consent. This was done in their classrooms, and surveys were then placed in sealed envelopes and returned to the researchers.

Data collection took place over a seven week period. All surveys were then mailed to the authors for analysis. All data from the surveys was transferred into a spreadsheet and then uploaded into SPSS for analysis. To minimize the possibility of data entry error, the process of transferring the data was done twice by different members of the research team.

\section{Data Analysis}

Six hundred and eighty seven surveys were retuned. After the data was transferred into a spreadsheet and uploaded into SPSS, it was checked for errors and outliers. Frequency distributions and descriptive statistics were run, and the data was analyzed, resulting in 3 surveys being eliminated from the data set. One had only 2 responses, and two others had illegible responses, making it impossible to determine their accuracy. That left 684 useable surveys. Forty-two had some missing data (usually one or two blank responses); however, they were retained for the study. The results from the survey are listed in Table 1.

Table 1: Survey results

\begin{tabular}{|l|c|c|}
\hline \multicolumn{1}{|c|}{ Type of Institution } & Number of participants & Percentage of Sample \\
\hline private not for-profit university & 241 & $35.2 \%$ \\
\hline public not for-profit university & 175 & $25.6 \%$ \\
\hline campus based for-profit university & 103 & $15.1 \%$ \\
\hline
\end{tabular}




\begin{tabular}{|l|c|c|}
\hline online for-profit university & 165 & $24.1 \%$ \\
\hline Totals & 684 & $100 \%$ \\
\hline
\end{tabular}

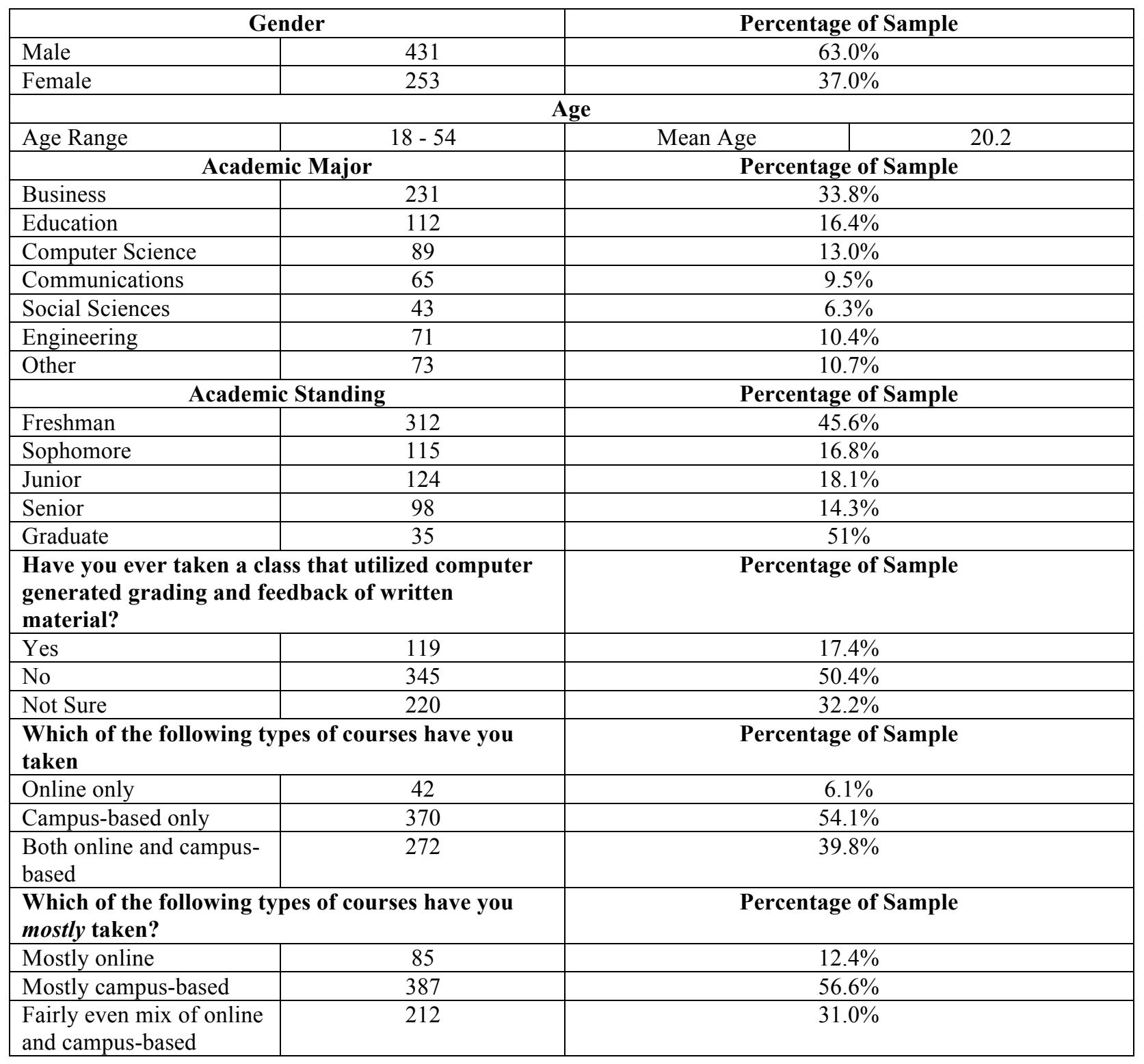

\begin{tabular}{|l|c|c|c|c|}
\hline \multicolumn{1}{|c|}{ Statement } & $\begin{array}{c}\text { Less than 24 } \\
\text { hours }\end{array}$ & $\begin{array}{c}\text { Within 1 } \\
\text { week }\end{array}$ & 1 to 2 Weeks & $\begin{array}{c}\text { More than 2 } \\
\text { weeks }\end{array}$ \\
\hline $\begin{array}{l}\text { How long do you think it should take a } \\
\text { faculty member to grade a short (less than 10 } \\
\text { page) essay? }\end{array}$ & 60 & 451 & 110 & 45 \\
\hline $\begin{array}{l}\text { How long do you think it should take a } \\
\text { faculty member to grade a major (10 or more } \\
\text { page) essay? }\end{array}$ & 18 & 233 & 326 & 104 \\
\hline \multicolumn{1}{|c|}{ Statement } & $\begin{array}{c}\text { All instructor } \\
\text { graded }\end{array}$ & $\begin{array}{c}\text { Majority } \\
\text { instructor }\end{array}$ & $\begin{array}{c}\text { Majority } \\
\text { computer }\end{array}$ & $\begin{array}{c}\text { All } \\
\text { computer }\end{array}$ \\
\hline
\end{tabular}




\section{Issues in Information Systems \\ Volume 14, Issue 1, pp.89-98, 2013}

\begin{tabular}{|l|c|c|c|c|}
\hline & & graded & graded & graded \\
\hline $\begin{array}{l}\text { What would be your preference for having } \\
\text { your own written assignments graded? }\end{array}$ & 333 & 195 & 104 & 28 \\
\hline
\end{tabular}

\begin{tabular}{|l|c|c|c|c|c|}
\hline \multicolumn{1}{|c|}{ Statement } & $\begin{array}{c}\text { SD } \\
\mathbf{( 1 )}\end{array}$ & $\begin{array}{c}\text { D } \\
\mathbf{( 2 )}\end{array}$ & $\begin{array}{c}\text { A } \\
\mathbf{( 3 )}\end{array}$ & $\begin{array}{c}\text { SA } \\
\text { (4) }\end{array}$ & Mean \\
\hline Timely grading and feedback of written work is important to me & 21 & 35 & 332 & 292 & 3.32 \\
\hline $\begin{array}{l}\text { Instructor's personal perceptions of a student influences how they } \\
\text { grade their written work }\end{array}$ & 69 & 155 & 267 & 191 & 2.18 \\
\hline $\begin{array}{l}\text { Usually Instructor feedback is adequate on written work I have } \\
\text { submitted }\end{array}$ & 46 & 215 & 315 & 105 & 2.72 \\
\hline Instructor feedback on written work improves my future writing & 109 & 267 & 248 & 59 & 2.77 \\
\hline $\begin{array}{l}\text { I value the personal nature of instructor feedback on my written } \\
\text { work }\end{array}$ & 84 & 111 & 360 & 125 & 2.77 \\
\hline I am most concerned with the final grade on written work & 26 & 120 & 181 & 355 & 3.27 \\
\hline Grading for written work is highly subjective & 102 & 118 & 402 & 59 & 2.61 \\
\hline $\begin{array}{l}\text { Computer generated grades and feedback on written work would } \\
\text { be of equal value to an instructor's }\end{array}$ & 165 & 375 & 101 & 41 & 2.03 \\
\hline $\begin{array}{l}\text { I appreciate both positive and constructive feedback on written } \\
\text { work }\end{array}$ & 59 & 141 & 315 & 165 & 2.86 \\
\hline $\begin{array}{l}\text { I would be accepting of a computer providing a final grade on } \\
\text { written work }\end{array}$ & 170 & 380 & 97 & 36 & 2.00 \\
\hline $\begin{array}{l}\text { A computer program is capable of effectively evaluating and } \\
\text { grading written work }\end{array}$ & 230 & 290 & 101 & 61 & 1.99 \\
\hline $\begin{array}{l}\text { Having faculty grade written assignment strengthens the } \\
\text { relationship between faculty and students }\end{array}$ & 42 & 280 & 310 & 49 & 2.54 \\
\hline Computer generated feedback is valuable in improving writing & 128 & 215 & 220 & 117 & 2.48 \\
\hline Computer generated grades are fair & 80 & 140 & 275 & 185 & 2.83 \\
\hline I would prefer to have my written work graded by a computer & 281 & 265 & 100 & 35 & 1.84 \\
\hline $\begin{array}{l}\text { Computer generated grades and feedback are appropriate for online } \\
\text { courses }\end{array}$ & 76 & 151 & 267 & 188 & 2.83 \\
\hline $\begin{array}{l}\text { I would be comfortable with any written work being entirely } \\
\text { evaluated by a computer }\end{array}$ & 185 & 310 & 110 & 79 & 2.12 \\
\hline $\begin{array}{l}\text { I would be concerned about signing up for a class in which all } \\
\text { writing assignments were graded by a computer program }\end{array}$ & 58 & 110 & 340 & 175 & 2.93 \\
\hline A written assignment graded by a computer would have less bias & 56 & 240 & 275 & 109 & 2.63 \\
\hline
\end{tabular}

The 20 items from the survey were subjected to principal component analysis (PCA) using SPSS Version 20. Prior to performing PCA, the suitability of data for factor analysis was assessed. Inspection of the correlation matrix revealed the presence of several coefficients of .3 and above. The Kaiser-Meyer-Oklin value was .77, exceeding the recommended value of .6 and Bartlett's Test of Sphericity reached significance, supporting the factorability of the correlation matrix $[2,11,12]$.

Principal component analysis revealed the presence of four components with eigenvalues exceeding 1 , explaining $45.8 \%, 18.6 \%, 7.3 \%$, and $5.1 \%$ of the variance respectively. A scree test and parallel analysis were also performed and validated that four components contributed to the structure [4]. The components were faculty relationship issues (statements 3,4,5,7, and 14), grade issues (statements 6,8, and 11), technology acceptance issues (statements 10, 12,13,15,18, and 21), and ethical/fairness considerations (statements 9,16,19, and 22). Statements 17 and 20 were used as measures of overall acceptance of PEG software by students. The selection of these grouping factors was based on both discussions with students in a small focus group (11 students) and the literature on the nature of grading $[1,3,5,8,29,31]$. Further testing on this instrument was done to establish reliability. With short subscales (generally fewer than 10 items) reliability can be established using the inter-item correlation for the items. The 


\section{Issues in Information Systems \\ Volume 14, Issue 1, pp.89-98, 2013}

recommended optimal range for inter-item correlations is .2 to .4 [21]. Each of the four subscales was within those parameters. Demographic variables were cross tabbed with individual statements on the survey as well as grouped perception issues developed from PCA. Those that demonstrated possible relationships were subjected to further analysis.

\section{FINDINGS}

Independent-sample t-tests were conducted to compare the four perception variables from the PCA with each of the demographic variables. Several, including gender, academic major, and age (grouped) showed no significant difference. The variable 'Which of the following types of courses have you taken' did reach statistical significance for students who had only taken online classes. However, the correspondingly low effect size (eta squared $=.02$ ) indicated that the magnitude of the relationship was small [21]. Two variables, 'type of institution attended' and 'familiarity with PEG utilization in classes' both reached significance $(\mathrm{p}<.05)$ and had moderate or high effect sizes. These were then subjected to ANOVA testing. A one-way between-groups analysis of variance was conducted to explore the impact of 'type of institution attended' and levels of positive perception of PEG software relating to each of the four grouped factors (faculty relationship, grades, technology acceptance, and ethics/fairness) as measured using the survey instrument. There were statistically significant differences in perception scores for students who attended both campus-based and online for-profit universities. The effect sizes for this variable are listed in Table 2.

Table 2: Effect Size for 'Type of institution attended' and Perception factors

\begin{tabular}{|l|c|c|}
\hline Perception Factor & Eta Squared & Analysis of Relationship \\
\hline Faculty issues & .05 & Moderate \\
\hline Grades & .35 & High \\
\hline Technology acceptance & .28 & High \\
\hline Ethics/Fairness considerations & .08 & Moderate \\
\hline
\end{tabular}

The emergence of 'type of institution attended' was an interesting finding. Several statements on the survey were indicative of the difference between these variables. A crosstab between type of institution attended and the question 'I would be comfortable with any written work being entirely evaluated by a computer' illustrates this dynamic (Table 3):

Table 3: Crosstab of 'type of institution attended' and 'I would be comfortable with any written work being entirely evaluated by a computer'

\begin{tabular}{|l|c|c|c|c|}
\hline Type of institution attended & $\begin{array}{c}\text { Strongly } \\
\text { disagree }\end{array}$ & Disagree & Agree & $\begin{array}{c}\text { Strongly } \\
\text { agree }\end{array}$ \\
\hline Private not-for-profit university & 44 & 165 & 19 & 13 \\
\hline Public not-for-profit university & 61 & 90 & 14 & 10 \\
\hline Campus based for-profit university & 28 & 20 & 36 & 19 \\
\hline Online for-profit university & 52 & 35 & 41 & 37 \\
\hline
\end{tabular}

Students attending the not-for-profit universities in this study either disagreed or strongly disagreed with the idea of being comfortable with the use of PEG software in $86.5 \%$ of the cases, while those attending for-profit universities either disagreed or strongly disagreed in only $50.4 \%$ of the cases. This indicated that those attending for-profit schools had a much likelier probability of accepting PEGs. Interestingly, while only $17.4 \%$ of the total sample was certain they had been exposed to PEGs, that percentage was even smaller for those that were exclusive to the forprofit schools (12.3\%), which may increase the perceived value of PEGs for students that attend these types of institutions.

A one-way between-groups analysis of variance was conducted then to evaluate the impact of 'familiarity with PEG utilization in classes' and the four perception variables. The ANOVA tests on 'familiarity with PEG utilization in 


\section{Issues in Information Systems \\ Volume 14, Issue 1, pp.89-98, 2013}

classes' reached statistical significance $(\mathrm{p}<.05)$ for both grades and technology acceptance, and each had a high effect size (eta squared for grades $=.58$ and for technology acceptance $=.62$ ).

Another interesting finding was the relationship between academic standing and perceptual issues regarding PEGs. ANOVA testing compared the means for academic standing and the four perceptual factors. Statistical significance was reached for three of the four factors (grades, technology acceptance, and ethical/fairness issues) for undergraduate students. Corresponding effect sizes revealed that only grades (eta squared $=.61$ ) was a largely meaningful factor for this population. However, graduate students' perceptions were much more focused on 'faculty relationship issues'. While both grades and faculty relationship issues reached significance in ANOVA testing, only the effect size for 'faculty relationship issues' was high (eta squared $=.62$ ).

Types of courses taken also had an influence on the perceptions of PEGs. A one-way between-groups analysis of variance was conducted to explore the influence of 'types of courses taken' on each of the four perceptual factors measured by the survey instrument. There was a statistically significant difference at $p<.05$ level in perception scores for students that were either 'online only' or 'campus-based only'. The effect size for 'online only' was moderate (eta squared $=.09$ ) and for 'campus-based only' was small (eta squared $=.03$ ).

In order to study the strength of the relationship between the four factors of perception and the willingness of students to accept PEG software, Spearman's Rho correlation coefficients were established between each of the grouped perception factors and overall acceptance of PEGs. Table 4 illustrates the relationship between these variables:

Table 4: Spearman's Rho Correlation Coefficients for Grouped Perception Factors and Overall Acceptance of PEGs

\begin{tabular}{|l|c|c|}
\hline Factor & Spearman's Rho & Significance (2 Tailed) \\
\hline Faculty relationship issues & .244 & .045 \\
\hline Grade issues & .788 & .000 \\
\hline Technology acceptance issues & .367 & .013 \\
\hline Ethics/Fairness issues & .339 & .004 \\
\hline
\end{tabular}

All of the variables reached statistical significance and the correlation between grade issues and student acceptance of PEGs was strong [21]. Each of the other factors had a moderate correlation to acceptance of PEGs; however, the dominant perceptual issue for students in this area is grades. Apparently, if students are convinced that a positive grade outcome can be achieved, they are very accepting of this technology.

\section{DISCUSSION}

The study revealed some interesting insights into the perceptions that college students have regarding the use of PEG software. The grouping of perception related issues regarding the use of PEGs proved highly interesting. The principal component analysis demonstrated the four major perceptual issues that college students consider when considering the use of PEGs in class. The emergence of grades as the primary consideration was not surprising, however, the low emphasis on faculty relationship issues (especially among undergraduates and online students) was an area that was somewhat striking. The mentoring relationship between faculty and students has long been perceived to be one of the bedrock elements of a college education, which, while almost impossible to measure, has traditionally been a source of value to both students and faculty. This study suggests that, for this population, the emphasis may be inaccurate. While it is likely that the distance of online education may contribute to that decline, it was surprising that this finding was relatively consistent for both online and campus based students.

The emergence of 'type of institution attended' was particularly striking. Students that attended for-profit institutions were more positive towards the PEG software on each perceptual dimension than students that attended not-for-profit schools. This difference was most pronounced for students that attended an online for-profit university. This group had very low scores on 'faculty relationship' issues. This may not be surprising, since the virtual environment makes establishing relationships with faculty challenging. The 'type of institution' attended has 


\section{Issues in Information Systems \\ Volume 14, Issue 1, pp.89-98, 2013}

interesting ramifications for the developers of PEG software since this study indicates that certain types of institutions (especially for-profit schools) may be more ready to have students accept PEGS than others. This insight could assist PEG developers in creating marketing strategies for this product.

Among the most important findings of this study is the relationship of grades to acceptance of PEG software. While the importance of grades to students has a long documented history $[3,8]$, the degree to which students seemed unconcerned who or what graded their work as striking. This was especially pronounced in students who had high expectations of quick turnaround times on essay grading. Table 5 illustrates this using a crosstab analysis of students who expected 24 hour turnaround time on short (less than 10 page) essay.

Table 5: Crosstab of students who responded 'less than 24 hours' to question 1 (How long do you think it should take a faculty member to grade a short (less than 10 page) essay? on the survey with question 17 'I would prefer to have my written work graded by a computer' on the survey

\begin{tabular}{|l|c|c|c|c|}
\hline & Strongly Disagree & Disagree & Agree & Strongly Agree \\
\hline Less than 24 hours & 4 & 16 & 18 & 22 \\
\hline All other options & 277 & 249 & 82 & 13 \\
\hline
\end{tabular}

Students who expected essays to be graded within 24 hours either agreed or strongly agreed with the statement 'I would prefer to have my written work graded by a computer' in $66.7 \%$ of the cases compared to the rest of the population which agreed or strongly agreed in only $15.3 \%$ of the cases. This indicates that for students that consider time a critical factor in grading, that PEGs may actually be considered an improvement over faculty grading.

Taken in its entirety, this study reveals a portrait of college students' perceptions regarding PEG software in classes. There is a disparity between undergraduate and graduate students, with undergraduates strongly considering grades to be the most important factor, and they seem unconcerned whether the grade comes from a professor or a computer. Graduate students, however, seem firmly convinced that the written work they submit forms a strong basis for their relationship with faculty, which they place high value on. This can be illustrated using a crosstab of student rank (combined undergraduate) and the question 'Having faculty grade written assignments strengthens the relationship between faculty and students' (Table 6).

Table 6: Crosstab of 'Student Rank' and 'Having faculty grade written assignments strengthens the relationship between faculty and students' statement from survey

\begin{tabular}{|l|c|c|c|c|}
\hline $\begin{array}{l}\text { Student } \\
\text { Demographic }\end{array}$ & Strongly Disagree & Disagree & Agree & Strongly Agree \\
\hline Undergraduate & 42 & 278 & 295 & 41 \\
\hline Graduate & 0 & 2 & 15 & 18 \\
\hline
\end{tabular}

In this crosstab, $94.3 \%$ of the graduate students either agreed or strongly agreed with this statement, indicating a very strong perception of the value of the relationship that develops between faculty and students, in regard to assessing their written work. It is not especially surprising that graduate students would place a high value on the assessment that faculty give them on written work, since such a large portion of graduate study is usually based on student research and writing. On the other hand, undergraduates only agreed or strongly agreed with this statement in $51.8 \%$ of the cases, indicating that undergraduate students are somewhat ambivalent regarding the degree to which having faculty assess their written work strengthens their relationships.

\section{CONCLUSIONS}

While it seems that most students have an initial preference for faculty-graded work $(80.0 \%$ preferred either all or majority faculty grading for written work), there were some demographic variables that had an influence on this perception. Increasing study of these factors and the influence they have on how students perceive the use of PEGs in the classroom, both online and on campus will increase the ability of producers of this software to meet the needs 


\section{Issues in Information Systems \\ Volume 14, Issue 1, pp.89-98, 2013}

of their target audience. It seems clear that technological advances will continue to occur in this field and that increasing numbers of schools will be interested in using this technology once it has been critically evaluated and student perceptions and concerns about this software are addressed. Therefore, increased understanding of perceptions of PEG software will continue to be an important issue for colleges and universities.

\section{AREAS FOR FUTURE RESEARCH}

While this study examined perceptual issues that college students considered when thinking about PEGs, another important component would be studying faculty perceptions on this issue, as well. There may be conflicting perceptions on the value of PEG software between students and faculty and a study on faculty perspectives might shed light on the differences between these two groups. It seems clear that, for this population, especially undergraduates, grades were the primary concern when perceiving the use of PEGs in classes. These students did not seem overly concerned with the mentoring and relationship aspects of their interaction with faculty, in regard to written work. A qualitative study investigating the deeper meaning of this variable might prove instructive. Another interesting area for further research was the degree to which the 'type of institution attended' influenced perception of PEGs. Further inquiry into this difference would be another interesting area of study.

Also, the instrument used to measure perceptions was an original creation of the authors. While the instrument proved valid and reliable and a relatively large population was subjected to the instrument, further use of this survey and its indexed subscales would provide additional reliability and validity data. Also, variation one the survey itself might prove valuable as well. A more expansive survey would allow for more statements to be included in each grouping. Since small subscales are often vulnerable to reliability concerns [21], additions to the survey could create an even more valid and reliable instrument.

\section{LIMITATIONS OF THE STUDY}

While the study has large or moderate amounts of data from all four 'types of institutions', it must be noted that all universities have unique and varying cultures. Even within a university, there can often be differences in perceptions and expectations between campus students and online students. The study also had a high percentage of males in the sample (63.0\%) which might have some influence on the results, although gender did not reach statistical significance as a variable. This study illustrates the possible dimensions that different groups within a student population might consider when perceiving the concept of PEG software, but any definitive conclusion on this issue will need further research and rigorous examination.

\section{REFERENCES}

1. Adams, J. B. (2005). What Makes the Grade? Faculty and Student Perceptions. Teaching Of Psychology, 32(1), 21-24.

2. Bartlett, M.S. (1954). A note on the multiplying factors for various chi square approximations. Journal of the Royal Statistical Society, 16 (Series B), 296-8.

3. Brookhart, S. M. 1994. Teachers' grading: Practice and theory. Applied Measurement in Education 7: $279-301$.

4. Catell, R. B. (1966). The scree test for number of factors. Multivariate Behavioral Research, 1, $245-76$.

5. Chory-Assad, R. M. 2002. Classroom justice: Perceptions of fairness as a predictor of student motivation, learning, and aggression. Communication Quarterly 50: 58-77.

6. Gaultney, J. F. \& Cann, A. (2001). Grade expectations. Teaching of Psychology, 28, 84-87.

7. Giles, J. (2012). Software gets top marks for grading student essays. New Scientist, 214(2861), 21.

8. Gordon, M. E., \& Fay, C. H. (2010). The Effects of Grading and Teaching Practices on Students' Perceptions of Grading Fairness. College Teaching, 58(3), 93-98.

9. Hoyt, W. T. (2000) Rater bias in psychological research: when is it a problem and what can we do about it? Psychological Methods, 5(1), pp. 64-86.

10. Hsu, T. C. \& Shermis, M. D. (1989) The development and evaluation of a microcomputerized adaptive placement testing system for college math, Journal of Educational Computing Research, 5(4), pp. 473-485.

11. Kaiser, H. (1970). A second generation little jiffy. Psychometrika, 35, 401-415.

12. Kaiser, H. (1974). An index of factorial simplicity. Psychometrika, 39, 31-6. 


\section{Issues in Information Systems \\ Volume 14, Issue 1, pp.89-98, 2013}

13. Johnson, V. E. (1996) On Bayesian analysis of multirater ordinal data: an application to automated essay grading, Journal of the American Statistical Association, 91(433), pp. 42-51.

14. Page, E. B. (1966) The imminence of grading essays by computer, Phi Delta Kappan, 48(1), pp. 238-243.

15. Page, E. B. (1994) Computer grading of student prose, using modern concepts and software, Journal of Experimental Education, 62(2), pp. 27-142.

16. Page, E. B. (1996) Grading essays by computer: why the controversy? Paper presented at the annual meeting of the National Council on Measurement in Education, April New York, NY.

17. Page, E. B., \& Paulus, D. H. (1968). The analysis of essays by computer (Final Report to the Bureau of Research at the U.S. Office of Education for Project 6-1318). Washington, DC: U.S. Department of Health, Education, and Welfare.

18. Page, E. B. \& Petersen, N. S. (1995) The computer moves into essay grading: updating the ancient test, Phi Delta Kappan, 76(7), pp. 561-565.

19. Page, E. B., Lavoie, M. J. \& Keith, T. Z. (1996) Computer grading of essay traits in student writing. Paper presented at the annual meeting of the National Council on Measurement in Education, April, New York, NY.

20. Page, E. B., Poggio, J. P. \& Keith, T. Z. (1997) Computer analysis of student essays: Finding trait differences in the student prose. Paper presented at the annual meeting of the American Educational Research Association, March, Chicago, IL.

21. Pallant J. (2007). SPSS survival manual: A step by step guide to data analysis using SPSS for windows (3 ${ }^{\text {rd }}$ edn). New York: McGraw Hill.

22. Sambell, K., L. McDowell, \& S. Brown, S. 1997. "But is it fair?" An exploratory study of student perceptions of the consequential validity of assessment. Studies in Educational Evaluation 23: 349-371.

23. Shermis, M. D., \& Burstein, J. (2003). Automated Essay Scoring : A Cross-disciplinary Perspective. Mahwah, N.J.: L. Erlbaum Associates.

24. Shermis, M. D., Wolting, M. \& Lombard, D. (1996) Development of a computerized test for college reading placement, Journal of Developmental Education, 20(2), pp. 18-24.

25. Shermis, M. D., Mzumara, H. R., Lillig, C. \& Brown, M. (1997) Computerized adaptive testing through the World Wide Web. Paper presented at the annual meeting of the American Psychological Association, August, Chicago, IL.

26. Shermis, M. D., Mzumara, H. R., Olson, J., \& Harrington, S. (2001). On-line Grading of Student Essays: PEG goes on the World Wide Web. Assessment \& Evaluation In Higher Education, 26(3), 247-259.

27. Shermis, M. D., Rasmussen, J. L., Rajecki, D. W., Olson, J. \& Marsiglio, C. (1999) Prompts and themes as sources of variance in grading college placement essays. Manuscript submitted for publication.

28. Smith, L. J. (2008). Grading Written Projects: What Approaches Do Students Find Most Helpful? Journal Of Education For Business, 83(6), 325-330

29. White, R., \& Dunlap, L. (1999, March). Student perceptions of the contribution of effort and performance in course grades. Paper presented at the 13th annual Conference on Undergraduate Teaching of Psychology, Ellenville, NY.

30. Wical, K., \& Mugele, R. (1993, January). PowerEdit analysis of prose: How the system is designed and works. Paper presented at the annual meeting of the North Carolina Association for Research in Education, Greensboro, NC.

31. Zak, F., \& Weaver, C. (Eds.). (1998). The theory and practice of grading writing: Problems and possibilities. Albany: State University of New York Press.

\section{Appendix A: Survey Instrument}

Survey on Student Perception on the use of Computer Programs (PEG) that grade student written work. Please mark the circle for each question that best approximates your response to the statement. Thank you for your participation in this study.

\section{Survey Questions}

1. How long do you think it should take a faculty member to grade a short (less than 10 page) essay?

Less than 24 hours Within a Week Within 2 Weeks More than 2 Weeks 


\section{Issues in Information Systems \\ Volume 14, Issue 1, pp.89-98, 2013}

2. How long do you think it should take a faculty member to grade a major (10 or more page) essay?

Less than 24 hours Within a Week Within 2 Weeks More than 2 Weeks

For the following statements, check the box that most closely approximates your opinion

$1=$ strongly disagree $\quad 2=$ disagree $\quad 3=$ agree $\quad 4=$ strongly agree

3. Timely grading and feedback of written work is important to me

4. Instructor's personal perceptions of a student influences how they grade their written work

5. Usually Instructor feedback is adequate on written work I have submitted

6. Instructor feedback on written work improves my future writing

7. I value the personal nature of instructor feedback on my written work

8. I am most concerned with the final grade on written work

9. Grading for written work is highly subjective

10. Computer generated grades and feedback on written work would be of equal value to an instructor's

11. I appreciate both positive and constructive feedback on written work

12. I would be accepting of a computer providing a final grade on written work

13. A computer program is capable of effectively evaluating and grading written work

14. Having faculty grade written assignments strengthens the relationship between faculty and students

15. Computer generated feedback is valuable in improving writing

16. Computer generated grades are fair

17. I would prefer to have my written work graded by a computer

18. Computer generated grades and feedback are appropriate for online courses

19. Computer generated grades and feedback are appropriate for campus-based courses

20. I would be comfortable with any written work being entirely evaluated by a computer

21. I would be concerned about signing up for a class in which all writing assignments were graded by a computer program

22. A written assignment graded by a computer would have less bias

23. What would be your preference for having your own written assignments graded?

\section{Demographics:}

24. Gender Male Female

25. Age

26. Academic major (Please circle the term that best describes your major course of study)

Business Education Computer Science Communication

Social Science Engineering Other

27. Academic Standing

Freshman Sophomore Junior Senior Graduate

28. Have you ever taken a class that utilized computer generated grading of written assignments?

Yes $\quad$ No

29. Which of the following types of courses have you ever taken

Online only Campus-based only Both online and campus-based

30. Which of the following types of courses have you mostly taken:

Mostly online Mostly campus-based Fairly even mix of online and campus based 